\title{
EDUCAÇÃO AMBIENTAL E SUSTENTABILIDADE NA PRÁTICA ESCOLAR
}

\author{
Leidryana da Conceição Ferreira ${ }^{1}$ \\ Leydiane da Conceição Gomes Ferreira Martins ${ }^{2}$ \\ Sueli Cristina Merotto Pereira ${ }^{3}$ \\ Désireé Gonçalves Raggi ${ }^{4}$ \\ Jose Geraldo Ferreira da Silva ${ }^{5}$
}

RESUMO: Falar de Educação Ambiental é uma necessidade urgente atualmente, principalmente na perspectiva de refletir sobre a responsabilidade social, visando criar um elo entre meio ambiente, sustentabilidade e educação. Isso porque se encontra enraizada na sociedade uma cultura de desperdício e despreocupação acerca de questões ambientais, que originaram leis direcionadas a promover o desenvolvimento econômico, mas também a assegurar a proteção do meio ambiente, além de estimular a sustentabilidade. Nesse sentido, pretende-se, neste trabalho, mostrar que é possível, por meio de práticas cotidianas, conscientizar crianças e jovens sobre Educação Ambiental, de forma que as futuras gerações estejam integradas ao meio ambiente. Para isso analisou-se um projeto desenvolvido em uma Escola Municipal de Educação Infantil e Ensino Fundamental, localizada no sul do Estado do Espírito Santo.

Palavras-chave: Educação Ambiental; Sustentabilidade; Prática Escolar.

\footnotetext{
${ }^{1}$ Faculdade Vale do Cricaré, E-mail: leidryana@hotmail.com

2 Faculdade Vale do Cricaré, E-mail: leydianecgfm@hotmail.com

${ }^{3}$ Faculdade Vale do Cricaré, E-mail: suelicmp@hotmail.com

${ }^{4}$ Escola Agrotécnica Federal de Santa Teresa, E-mail: desireeraggi@yahoo.com.br

${ }^{5}$ Faculdade Vale do Cricaré Instituto Capixaba de Pesquisa Assistência Técnica e Extensão Rural.

E-mail: j.geraldo525@gmail.com
} 


\section{Introdução}

O homem vivia uma relação harmônica com a natureza e dela dependia integralmente para sobreviver. Com o desenvolvimento das ciências, a capacidade de compreensão do homem se expandiu e daí surgiu a ideia de subjugar a natureza em benefício próprio. Porém, a evolução trouxe também o desenvolvimento de condutas inadequadas referentes ao meio ambiente, especificamente, por meio do desperdício e da degradação ambiental.

A expressão Educação Ambiental surgiu no ano de 1965, com o termo "Environmental Education", na Conferência em Educação na Universidade Keele, destacando a formação de todos os cidadãos relacionada a problemas ambientais que envolvem a humanidade.

A Educação Ambiental estimula a conscientização do indivíduo acerca dos problemas ambientais, bem como define diretrizes para combatê-los, principalmente por meio da conservação das reservas naturais e de sugestões de práticas antipoluentes. É uma vertente da Educação direcionada a assuntos que envolvem a interação homem-ambiente, e visa despertar uma consciência crítica sobre os problemas ambientais. Estimula também o indivíduo a desenvolver um caráter mais complexo e realista, considerando o ambiente em sua totalidade. Facilita a compreensão do ambiente como conjunto de relações entre os seres vivos e os não vivos ao conduzir esse indivíduo à percepção de que os problemas ambientais não podem e não devem ser tratados com neutralidade, mas precisam ser resolvidos com a mudança da relação entre a sociedade com a natureza. Esse aprendizado e essa conscientização devem ser abordados na infância, na fase da Educação Infantil, do Ensino Fundamental e Médio, pois os adultos já desenvolveram hábitos difíceis de mudar. A escola transforma-se, assim, no espaço mais eficaz para formar e preparar esses indivíduos para viver em sociedade e em seu ambiente físico.

Entretanto, a transformação do modo de vida da sociedade, o aumento da violência e a explosão populacional impactaram, sobremaneira, a infância das crianças. $\mathrm{O}$ que antes era senso comum - brincadeiras nas ruas, andar de bicicleta, jogar futebol nos campinhos - hoje é considerado inviável, devido à violência nas cidades. As crianças afastaram-se do contato com a natureza e muitos não conhecem os elementos naturais que compõem o meio que os cerca, somente pela televisão ou por meios eletrônicos. Diante dessa constatação, da escola assume um papel preponderante como recurso imprescindível para despertar na criança e nos jovens, futuro cidadão, o interesse e o conhecimento da diversidade ambiental ainda existente.

Nesse sentido, a Educação Ambiental nas escolas atua como agente formador de cidadãos mais conscientes e os torna aptos a atuar na realidade socioambiental que os cerca. A escola, mais do que conceitos e informações, deve trabalhar com atitudes e ações práticas, de modo que o aluno possa aprender a praticar ações direcionadas à preservação e à conservação ambiental. No espaço escolar, o aluno complementa sua socialização, portanto, deve vivenciar diariamente a prática de bons hábitos sociais e ambientais. Os 
professores devem desenvolver a consciência de que não são os detentores do saber e procurar, junto a outros profissionais, subsídios para que a Educação Ambiental na instituição seja uma prática diária e constante e se torna um hábito a ser incorporado à vida cotidiana. Para isso, o professor precisa aprender e descobrir novas práticas pedagógicas visando despertar a consciência da necessidade de conservar o ambiente em que vivemos, estimulando também a sustentabilidade.

No que se refere à sustentabilidade, para Cavalcanti (2001, p.165):

O desenvolvimento econômico não representa mais uma opção aberta, com possibilidades amplas para o mundo. A aceitação geral da ideia de desenvolvimento sustentável indica que se fixou voluntariamente um limite (superior) para o progresso material. Adotar a noção de desenvolvimento sustentável, por sua vez, corresponde a seguir uma prescrição política. 0 dever da ciência é explicar como, de que forma, ele pode ser alcançado, quais são os caminhos para a sustentabilidade.

É preciso pensar de forma consciente em desenvolvimento econômico, em tecnologias, mas também em qualidade de vida e sustentabilidade ambiental. Nesse cenário, a sociedade precisa elaborar e implantar soluções concretas em que todas as esferas - econômica, política e social - por meio de esforços mútuos, na perspectiva de que o desenvolvimento seja sustentável. $\mathrm{O}$ meio ambiente não suporta mais tanta agressividade, nem a exploração desordenada de seus recursos para fins econômicos, tornando perceptíveis inúmeros problemas ambientais.

Pelo exposto e com base nesses conceitos, foi desenvolvido em uma escola pluridocente do município de Presidente Kennedy, no sul do Estado do Espírito Santo, um projeto com o intuito de despertar nos alunos o interesse pela Educação Ambiental e Sustentabilidade, por meio da proposição de novas práticas ambientais e sociais nos diferentes ambientes em que se encontram inseridos.

\section{A legislação ambiental brasileira}

A maioria dos nossos problemas ambientais tem suas raízes em fatores culturais, políticos e socioeconômicos, não podendo ser resolvidos por meios puramente tecnológicos. Abordar esses problemas somente sob o aspecto ecológico é desconhecer, ingenuamente, a realidade desfavorável que precisa ser modificada. Assim, para que as questões ambientais sejam compreendidas e visando solucionar problemas decorrentes de práticas prejudiciais ao meio ambiente foram elaboradas leis que garantem a obrigatoriedade da preservação e da sustentabilidade do meio ambiente.

revista brasileira educação ambiental 
No Brasil, o marco inicial mais importante e abrangente é o Código Florestal - Lei no 4.771, instituída em 15/09/1965, que determina como área de preservação permanente as matas ciliares em torno dos cursos d'água nas margens dos rios, lagoas e reservatórios, matas em topos de morro e proteção às matas nativas.

A Constituição Federal Brasileira de 1988 traz um avanço significativo relacionado às leis que instituem a preservação e a proteção ambiental. A partir de então, o meio ambiente passou a ser assegurado como bem comum de toda a sociedade, atribuindo responsabilidades ao Estado e à população. $A$ Constituição Federal de Brasil (1988, título VIII, Cap. VI), institui em seu art. 225 que:

Todos têm direito ao meio ambiente ecologicamente equilibrado, bem de uso comum do povo e essencial à sadia qualidade de vida, impondo-se ao Poder Público e à coletividade o dever de defendê-lo e preservá-lo às presentes e futuras gerações.

A Lei no 6.938/81, que instituiu a Política Nacional do Meio Ambiente, é uma das mais importantes leis ambientais, pois define que o poluidor passa ser responsável por seus prejuízos e danos ambientais, tornando-se obrigatória a indenização, independentemente da culpa, por agressões ao meio ambiente; tal lei fomentou estudos e a criação de relatórios de impactos ambientais (EIA, RIMA).

Além dessas legislações mais amplas, a Política Nacional de Educação Ambiental institui a Educação Ambiental como um componente essencial e permanente da educação em caráter formal e não formal em todo o país, articulada e presente em todos os níveis e modalidades de ensino, inserido de forma interdisciplinar e transversal ao currículo escolar.

A discussão sobre a relação educação - meio ambiente contextualizase em um cenário atual de crise em todas as dimensões - econômica, política, cultural, social, ética e ambiental. Para superá-la, tem sido apresentado em diversos fóruns o modelo de desenvolvimento sustentável, que propõe associar desenvolvimento econômico com preservação do meio ambiente. Nesse sentido, um dos temas apresentado nesses fóruns é a Educação Ambiental como instrumento para alcançar os objetivos propostos.

\section{Educação Ambiental}

Entende-se Educação Ambiental como o processo percorrido pelo educando em busca de conhecimento sobre questões ambientais, com a finalidade de desenvolver uma nova percepção a respeito do conceito de meio ambiente, bem como se tornar também um agente transformador da conservação e da preservação dos recursos naturais. 
Para isso, a escola, por ser um espaço social e de constante aprendizagem, contribui para a formação de cidadãos conscientes, responsáveis e atentos à relação homem - ambiente. Nesse espaço, a Educação Ambiental tornou-se um componente essencial no processo de formação, visto que perpassa todos os segmentos e currículos escolares. Por se tratar de uma temática interdisciplinar, a EA precisa ser desenvolvida de forma contínua, permanente, sistemática e transversal, contextualizando tais conteúdos com a realidade integral do mundo contemporâneo.

A prática de projetos e pesquisas, realizada por meio de temas geradores e estudados de maneira interdisciplinar precisa se consolidar na fundamentação teórica. Assim sendo, para Leff (2001, p.218):

O desenvolvimento de programas de Educação Ambiental e a conscientização de seus conteúdos depende deste complexo processo de emergência e constituição de um saber ambiental, capaz de ser incorporado às práticas docentes e como guia de projetos de pesquisa.

A sensibilização é um sentimento ou emoção que a escola pode provocar, uma vez que a EA destina-se a todos e é ofertada por meio da educação formal, da Educação Infantil até o Ensino Superior, inclusive na formação de professores e outros profissionais; e da não formal, que abrange todos os demais segmentos da população que dispõem de poder ou não nas áreas ambientais (CARTA DE BELGRADO, 1975). No entanto, a conscientização vai além da sensibilização, ela provoca mudanças de comportamentos e concepções no indivíduo quando este aprende e compreende que cada ser humano integra o meio ambiente e que é necessário fazer sua parte em cuidar, respeitar e preservar o ambiente em que vive, de forma a garantir a sobrevivência para as gerações futuras.

Assim, com o intuito de estimular a formação de uma nova percepção individual e pessoal, a Carta de Belgrado (1975, p.2/3) considera como objetivos da Educação Ambiental:

Tomada de consciência: Ajudar às pessoas e aos grupos sociais a adquirir maior sensibilidade e consciência do meio ambiente em geral e dos problemas.

Conhecimentos: Ajudar às pessoas e aos grupos sociais a adquirir uma compreensão básica do meio ambiente em sua totalidade, dos problemas associados e da presença e função da humanidade neles, o que necessita uma responsabilidade crítica.

Atitudes: Ajudar às pessoas e aos grupos sociais a adquirir valores sociais e um profundo interesse pelo meio ambiente 
que os impulsione a participar ativamente na sua proteção e melhoria.

Aptidões: Ajudar às pessoas e aos grupos a adquirir as aptidões necessárias para resolver os problemas ambientais.

Capacidade de avaliação: Ajudar às pessoas e aos grupos sociais a avaliar as medidas e os programas de Educação Ambiental em função dos fatores ecológicos, políticos, sociais, estéticos e educativos.

Participação: Ajudar às pessoas e aos grupos sociais a desenvolver seu sentido de responsabilidade e a tomar consciência da urgente necessidade de prestar atenção aos problemas ambientais, para assegurar que sejam adotadas medidas adequadas

Com essa perspectiva, a escola, espaço de formação e transformação, precisa assegurar que os objetivos da Carta de Belgrado sejam viabilizados e consolidados na prática cotidiana dos educandos, bem como discutidos com a comunidade. E também considerando que nesse espaço de vivência é necessário tratar de temas da atualidade aplicados à realidade cotidiana dos seus alunos, os Parâmetros Curriculares Nacionais, do tema transversal Meio Ambiente estabelecem que:

Temas da atualidade, em contínuo desenvolvimento, exigem uma permanente atualização; e fazê-lo junto com os alunos é uma excelente oportunidade para que eles vivenciem o desenvolvimento de procedimentos elementares de pesquisa e construam, na prática, formas de sistematização da informação, medidas, considerações quantitativas, apresentação e discussão de resultados etc. O papel dos professores como orientadores desse processo é de fundamental importância. Essa vivência permite aos alunos perceber que a construção e a produção dos conhecimentos são contínuas e que, para entender as questões ambientais, há necessidade de atualização constante (BRASIL, 1997, p.188).

Os problemas ambientais são o resultado da exploração dos recursos naturais pela sociedade capitalista, bem como do consumismo e da industrialização, gerados pelo ser humano ao utilizá-los em seu benefício. 0 meio ambiente possui recursos finitos, até então explorados sem qualquer preocupação quanto à sua escassez, porém, apesar disso, o homem conseguiu perceber a crise ambiental, a qual efetivamente afeta toda a vida no planeta. Por isso, desenvolver a criticidade é fundamental para a formação dos alunos, oportunizando a construção do conhecimento cotidianamente. 


\section{Sustentabilidade}

Por décadas a humanidade vem usufruindo dos recursos naturais de forma imprudente e inconsciente, como se fossem infinitos, causando um grande impacto ambiental. Estudos são realizados visando solucionar os problemas decorrentes dessas ações, porém a sociedade precisa aprender a viver de maneira sustentável, aproveitando melhor os recursos naturais e com índices menores de degradação ambiental. Para isso, é preciso ir além dos conceitos existentes de sustentabilidade, é necessário estimular ações e posturas voltadas a repensar e refletir acerca das atitudes praticadas, bem como propor novas condutas que favoreçam o meio ambiente. Ao sensibilizar cada educando na escola por meio de uma Educação Ambiental consciente e, consequentemente, seu círculo familiar, estenderá o alcance dela a um maior número de possível de pessoas.

Além disso, o desenvolvimento sustentável deve ser uma consequência do desenvolvimento social, econômico e da preservação ambiental. (JACOBI, 1997; RUSCHEINSKY, 2004; GUIMARÃES, 2001 apud SILVA 2012).

O desenvolvimento sustentável não refere especificamente a um problema limitado de adequação ecológica de um processo social, mas a uma estratégia ou modelo múltiplo para a sociedade, que deve levar em conta tanto a viabilidade econômica quanto ambiental. Num sentido abrangente, a noção de desenvolvimento sustentável remete à necessária mudança substancial do próprio processo civilizatório. Entretanto, a falta de especificidade e as pretensões totalizadoras tem tornado o conceito de desenvolvimento sustentável, difícil de ser classificado em modelos concretos e operacionais e analiticamente precisos. Por isso, ainda é possível afirmar que não se constitui num paradigma no sentido clássico do conceito, mas uma orientação ou enfoque, ou ainda uma perspectiva que abrange princípios normativos.

O futuro de várias espécies depende da ação humana no meio ambiente; a qualidade de vida da população é diferente de épocas anteriores; animais e algumas plantas estão extintos e o índice de poluição encontra-se em níveis altíssimos. Existe a incerteza de um lugar onde as gerações futuras possam viver com o mínimo de qualidade. O homem tornou-se incapaz de usufruir dos recursos naturais visando o bem comum. Nesse sentido, segundo a Carta da Terra (2002, p.01):

Estamos diante de um momento crítico na história da Terra, numa época em que a humanidade deve escolher seu futuro. À medida que o mundo torna-se cada vez mais interdependente e frágil, o futuro enfrenta, ao mesmo tempo, grandes perigos e grandes promessas. Para seguir adiante, devemos reconhecer 
que, no meio de uma magnífica diversidade de culturas e formas de vida, somos uma família humana e uma comunidade terrestre com um destino comum. Devemos somar forças para gerar uma sociedade sustentável global baseada no respeito pela natureza, nos direitos humanos universais, na justiça econômica e numa cultura da paz. Para chegar a este propósito, é imperativo que nós, os povos da Terra, declaremos nossa responsabilidade uns para com os outros, com a grande comunidade da vida, e com as futuras gerações.

Inúmeras são as ações que o homem pode efetivar para reverter a degradação ambiental, começando na própria casa, ao separar o lixo para a coleta seletiva, não jogar lixo no chão etc. Porém, isso não é o bastante, tendo em vista que vivemos em uma cultura capitalista-industrial; assim, urge estimular um desenvolvimento sustentável, com alguns parâmetros a serem seguidos (Figura 1).

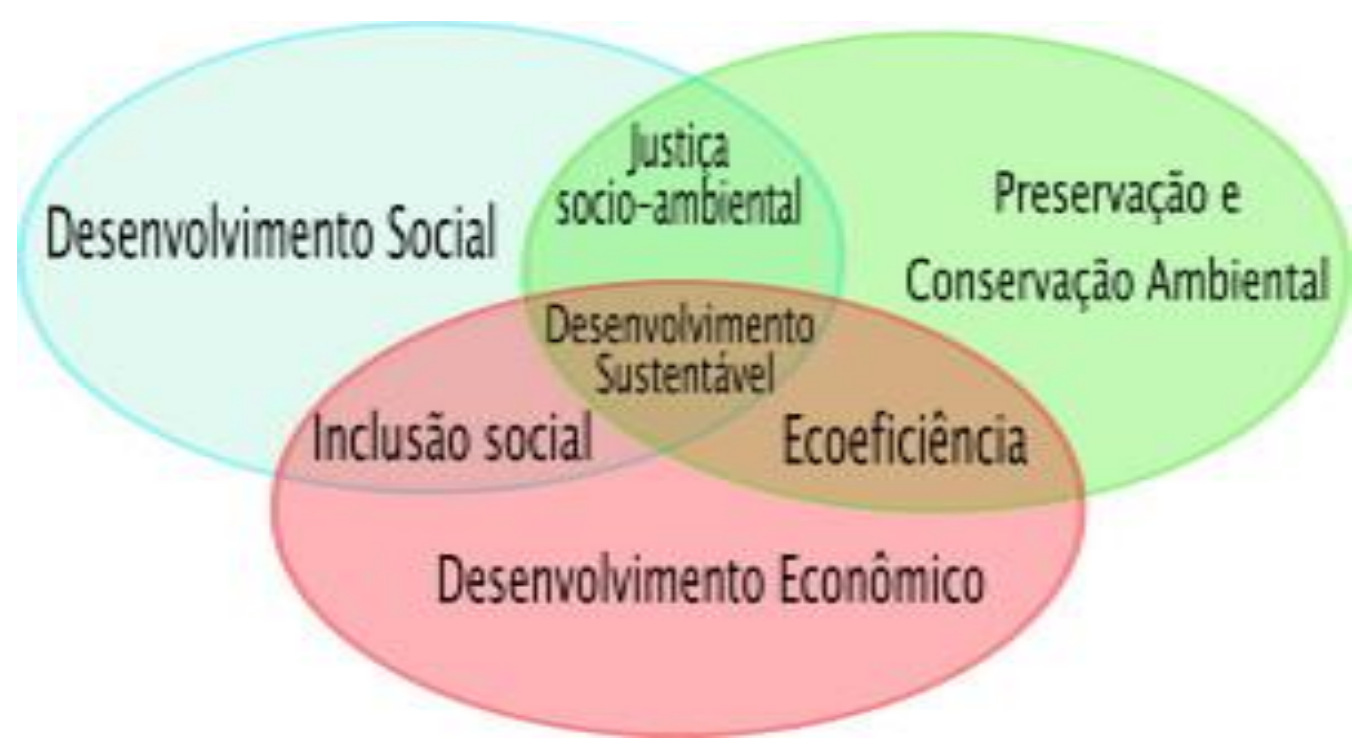

Figura 1: Desenho esquemático relacionando parâmetros para alcançar o desenvolvimento sustentável. Fonte: (BARBOSA, 2008).

O desenvolvimento sustentável permeia métodos de construção e recursos que não impactam no meio ambiente, visa proporcionar qualidade de vida, bem como garantir um futuro melhor para a geração atual e as gerações vindouras.

\section{O contexto do campo de pesquisa}

A presente pesquisa-ação foi desenvolvida em uma escola pluridocente do município de Presidente Kennedy, ES, que atende 101 alunos do $1^{\circ}$ ao $5^{\circ}$ ano do Ensino Fundamental. Foi aplicado um questionário a 10 docentes e 70 
alunos do $3^{\circ}$ ao $5^{\circ}$ ano do Ensino Fundamental para mensurar seus conhecimentos sobre questões relacionadas ao meio ambiente. O questionário proposto aos alunos era composto por quinze perguntas objetivas sobre o assunto. $O$ questionário proposto aos docentes tinha dez perguntas sobre a grade curricular disponibilizada aos alunos, envolvendo Educação Ambiental e Sustentabilidade.

\section{Resultados e discussão}

Os professores que responderam ao questionário atuam na educação há dez anos ou mais. Deles, sete afirmaram que trabalham a Educação Ambiental de forma fragmentada, abordando o assunto, principalmente, nas aulas de Ciências (Figura 2). Responderam também que é muito difícil interligar esse assunto às disciplinas de Matemática e Português, devido à grade curricular proposta pela Secretaria de Educação. Todos afirmaram conhecer a importância do assunto e sabem que a Educação Ambiental é um processo dinâmico e em permanente construção, porém ainda não faz parte da rotina diária da prática pedagógica, sendo abordado de forma contumaz apenas por 2 deles.
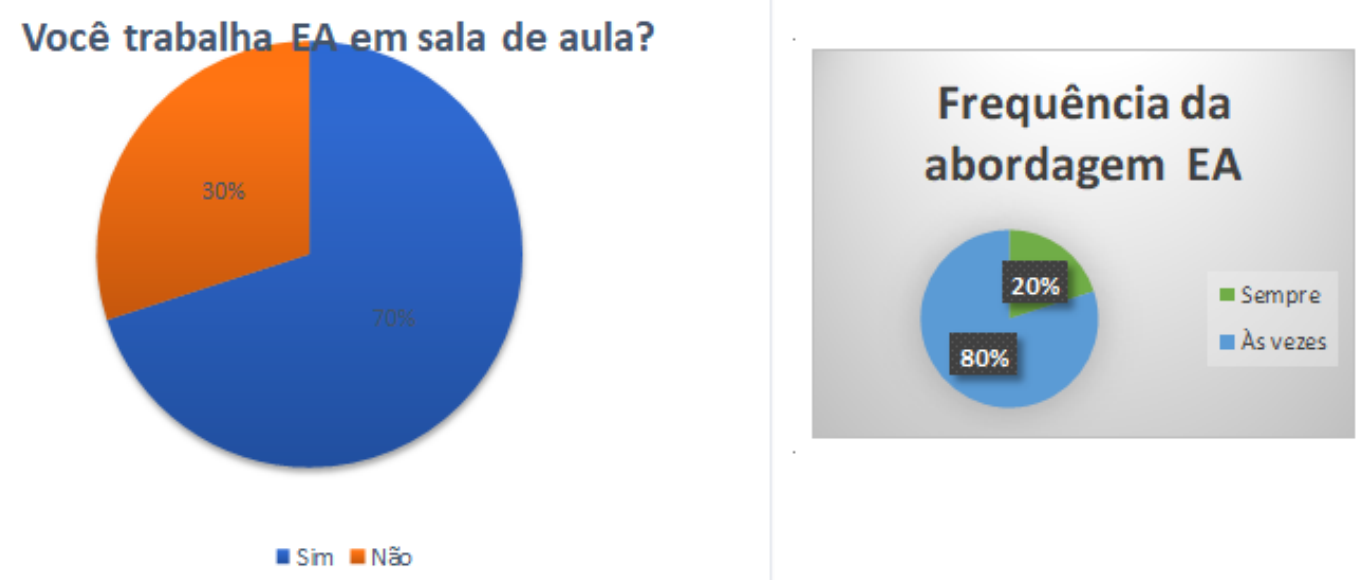

Figura 2: Frequência de trabalho com EA em sala de aula. Fonte: Autores (2018)

Ao serem questionados sobre a importância de introduzir a Educação Ambiental como disciplina no currículo escolar, todos responderam sim, justificando a necessidade de abordar o tema diariamente, com a mesma frequência das outras disciplinas. Ao serem questionados acerca da forma de aplicação do assunto, responderam que deveria ser de forma interdisciplinar, perpassando todas as disciplinas. Essa resposta demonstra um conflito de conhecimentos dos docentes sobre interdisciplinaridade ${ }^{6}$, visto que, se

\footnotetext{
${ }^{6}$ Interdisciplinaridade: conceito o que é um comum a duas ou a mais disciplinas, diz respeito ao processo de ligação entre as disciplinas.
} 
colocada como disciplina na grade curricular, a Educação Ambiental seria tratada de forma isolada, com seus conteúdos estabelecidos e não alcançaria seu maior objetivo, que é o de permear a vida do indivíduo em todos seus aspectos.

Os docentes também foram questionados sobre a maneira de abordar a Educação Ambiental em sua prática pedagógica (Figura 3), sendo que a maioria disse que faz de maneira bastante diversificada, com projetos, leituras informativas e visitas à Associação de Artesãos da comunidade.

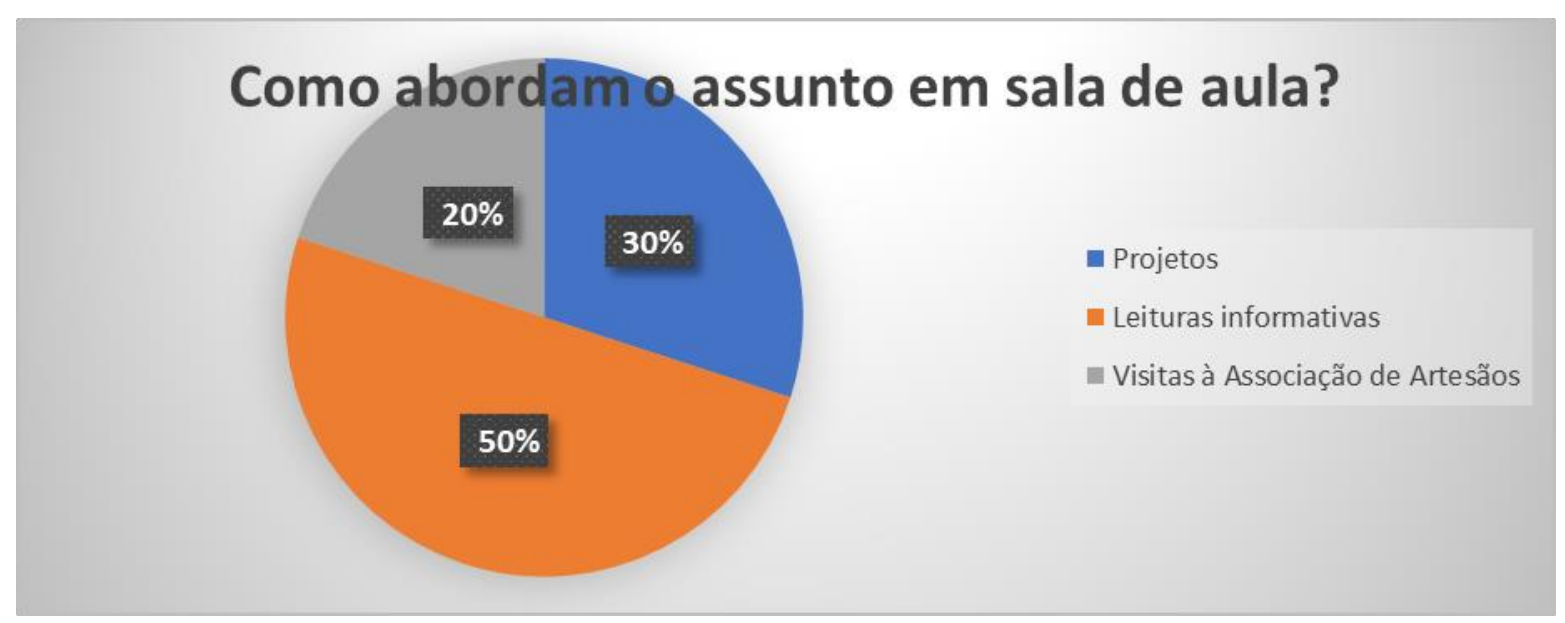

Figura 3: Forma de abordagem da EA em sala de aula. Fonte: Autores (2018)

Ao serem questionados se recebem capacitação profissional para ministrar EA em sua sala de aula, a maioria disse não, justificando que seus conhecimentos são adquiridos por meio de buscas pessoais para incrementar a prática pedagógica (Figura 4).

\section{Você recebe/recebeu capacitação profissional para trabalhar EA em sala de aula?}

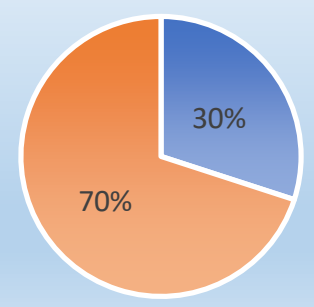

Figura 4: Capacitação dos professores para EA. Fonte: Autores (2018)

Além desses tópicos, os docentes também responderam sobre seus conhecimentos sobre Sustentabilidade (Figura 5). O grupo, em sua maioria, conhece o tema superficialmente, não o coloca em prática no dia a dia. 
Reconheceram também que seus hábitos de consumo contradizem o conceito sustentável necessário para a preservação do planeta.

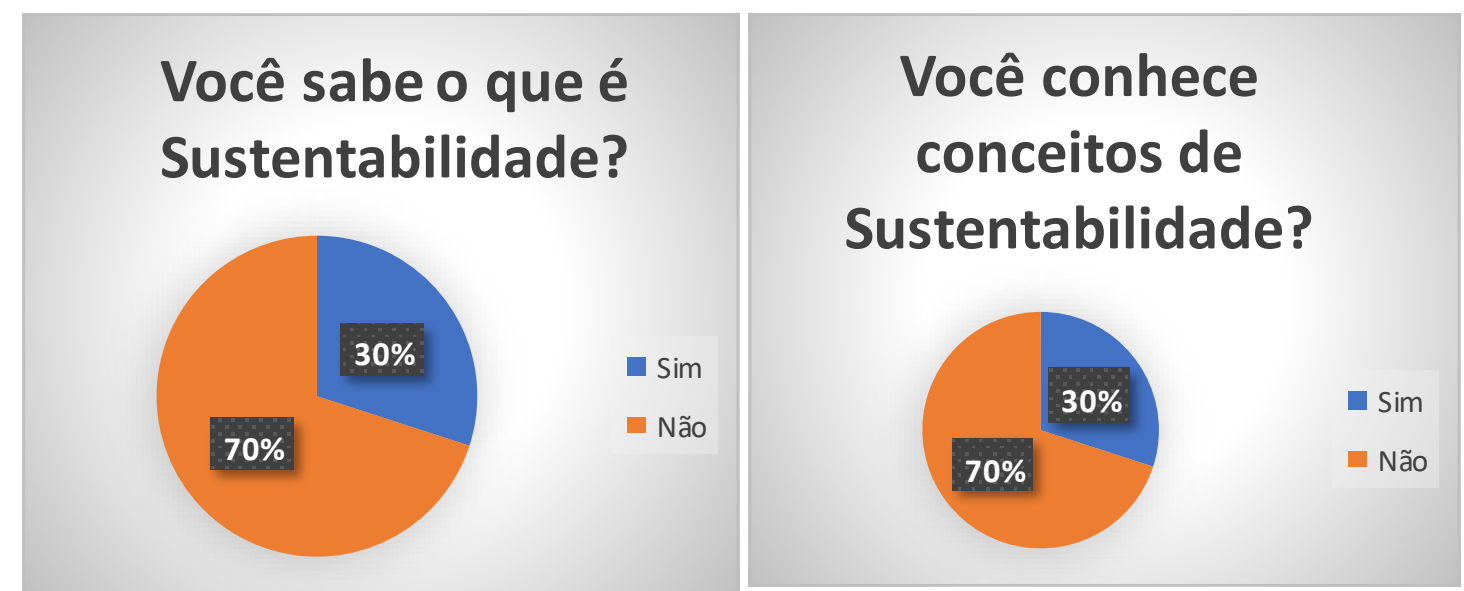

Figura 5: Conhecimentos dos professores sobre Sustentabilidade. Fonte: Autores (2018).

No que se refere ao questionário aplicado aos 60 alunos, 45 responderam que já ouviram falar de Educação Ambiental (Figura 6A), e 39 responderam que os professores abordam o tema em suas aulas, mas que gostariam de saber mais sobre o assunto.

Quanto à forma de trabalho dos docentes, 48 alunos responderam que recebem material de leitura para debate, realizam visitas à Associação de Artesanato local e participam de rodas de conversa; 20 deles apontaram participar de projetos de reciclagem e horta escolar (Figura 6B).

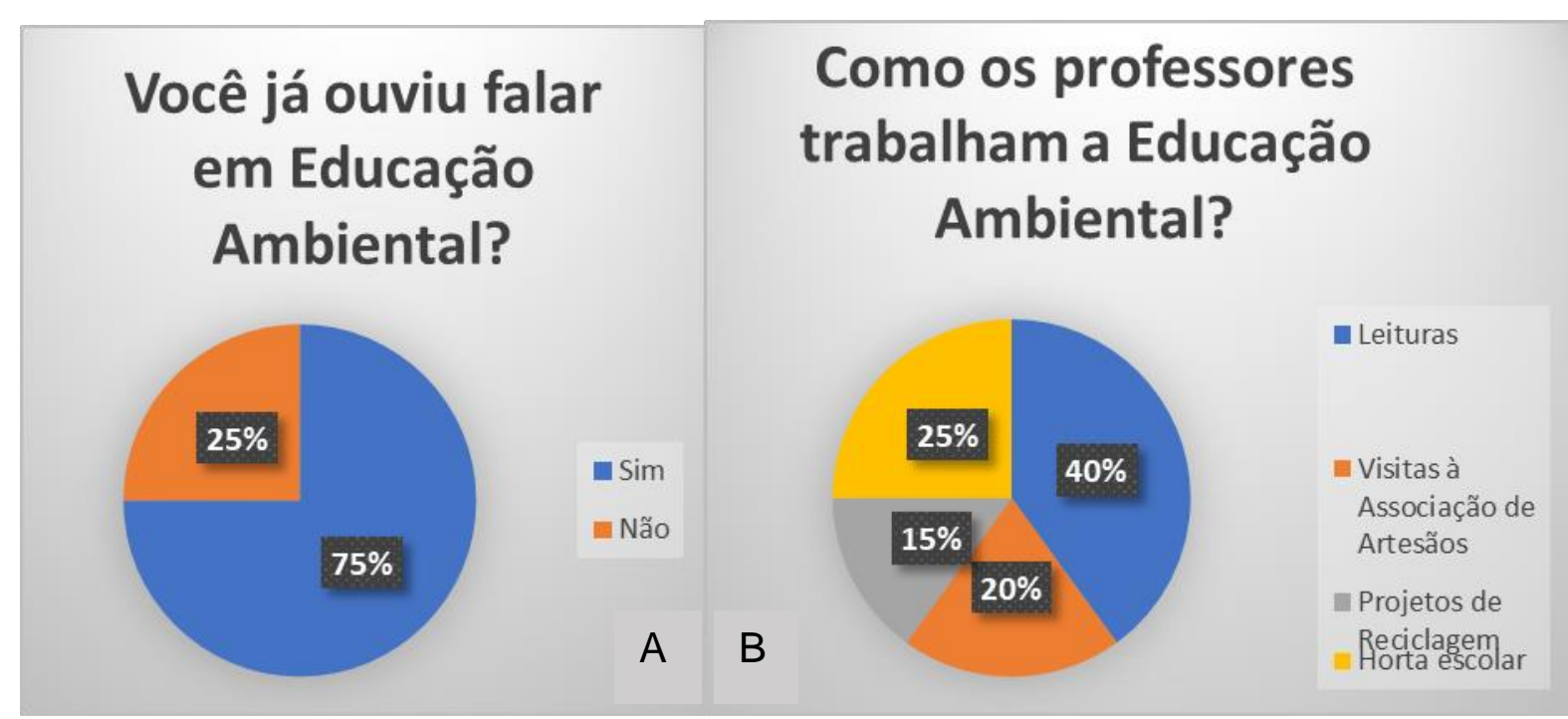

Figura 6: Forma de trabalho com EA pelos professores. Fonte: Autores (2018) 
Após aplicar os questionários e de posse dos resultados, os professores decidiram desenvolver um projeto visando sensibilizar os educandos em relação à questão ambiental. A finalidade foi proporcionar a eles a aquisição de conhecimentos científicos e estimular atitudes éticas, para que possam participar efetivamente nos processos de desenvolvimento e proteção ao meio ambiente de sua comunidade.

Além disso, de acordo com a Lei oㅡ 6.938/81, que determina em seu art. 2ㅜㄹ inciso $\mathrm{X}$, que "Educação Ambiental a todos os níveis do ensino, inclusive a educação da comunidade, objetivando capacitá-la para participação ativa na defesa do meio ambiente", os professores visualizaram uma grande possibilidade para conscientizar os alunos e, assim, transformá-los em agentes multiplicadores da defesa do meio ambiente.

Nesse contexto propuseram aos alunos realizar a limpeza do bairro em que a escola está inserida, pois percebem nas ruas uma grande quantidade de lixo descartado de forma irregular, principalmente garrafas pet, bem como o desconhecimento de práticas corretas para preservar o meio ambiente por parte dos educandos e seus familiares. Estabeleceram como princípio das atividades uma gincana ecológica, em que cada grupo, determinado por cores, recolheria garrafas pet para serem utilizadas na confecção de uma horta no espaço escolar. Essa horta servirá de estímulo a uma alimentação mais saudável, outra proposta feita pelos docentes aos alunos. Após a coleta, iniciou-se, a construção da sementeira e a coleta de adubo orgânico em um sítio local, atividade acolhida com entusiasmo. Após duas semanas ocorreu o transplante das mudas, por meio do qual foram desenvolvidas atividades teóricas, pois os alunos, curiosos, buscavam respostas para suas indagações. A cada manhã, eles iam ao local de plantio para regar e acompanhar o crescimento das mudas. A partir daí abriu-se um leque muito amplo de atividades, abrangendo Língua Portuguesa, com leituras informativas diversas; Matemática, com resolução de problemas e sistema monetário; Ciências, com o ciclo de vida dos vegetais, as partes das plantas, a germinação, as vitaminas obtidas com no consumo dos vegetais, a água e a poluição; Geografia, com análise e tipos de solo; História, com o conhecimento dos hábitos alimentares da humanidade e as consequências do progresso (poluição, desmatamento, consumo desenfreado). Os alunos mostraram-se entusiasmados com as atividades e, ao mesmo tempo, os professores começaram a realizar o trabalho de conscientização, visando despertar neles atitudes críticas como sujeitos de consumo e responsáveis por suas ações.

A atividade desenvolvida mostrou-se uma ferramenta eficaz para despertar a conscientização desses alunos e será realizada de forma contínua, visando formar e capacitá-los para a preservação e conservação do ambiente em que vivem. Já no final do primeiro mês observou-se uma mudança no comportamento dos alunos, pois seus responsáveis iam à escola e relatavam as atitudes e os questionamentos dos filhos, a preocupação deles com o espaço da comunidade, destacando também a mudança dentro de seu próprio lar.

Revbea, V. 14, № 2: 201-214, 2019. 


\section{Considerações finais}

A aquisição de novos conhecimentos estimula o desenvolvimento de uma nova visão do mundo que nos cerca. A escola configura-se como espaço privilegiado para a construção de hábitos conscientes, desenvolve o senso crítico e oportuniza a elaboração de novas práticas pedagógicas.

A Educação Ambiental nas escolas tem um papel muito importante porque desperta em cada aluno a busca de soluções para os problemas ambientais que ocorrem, principalmente, em seu cotidiano e no desenvolvimento da consciência de é imprescindível utilizar com inteligência os recursos naturais. Estimular a mudança de atitude, em busca de qualidade de vida, bem como o respeito à natureza e a compreensão de que somos agentes de transformação da sociedade representa o ápice da prática pedagógica.

Esta pesquisa-ação proporcionou identificar aspectos referentes à Educação Ambiental e Sustentabilidade que ainda necessitam ser incorporados à vivência diária da escola em questão, ao mesmo tempo em que despertou nos professores e alunos o entusiasmo e o compromisso de cultivar hábitos mais saudáveis e atitudes eficientes diante do problema ambiental.

\section{Referências}

A CARTA DE BELGRADO. Disponível em: swww.ebah.com.br/content/ ABAAABF1YAL/a-carta-belgrado>. Acesso em: 25 abr. 2018.

BARBOSA, G. S. O desafio do desenvolvimento sustentável. Revista Visões, v. 1, n. 4, p. 1-11, jun. 2008.

CARTA DA TERRA, 1992, Disponível em:<www.cartadaterra.com.br $>$ Acesso em: 25 abr. 2018.

CAVALCANTI, C. Desenvolvimento e natureza: estudos para uma sociedade sustentável. 3. Ed. São Paulo: Cortez, 2001.

BARBOSA, G.S. O desafio do desenvolvimento sustentável. Revista Visões $4^{a}$ Edição, №4, Volume 1 - Jan/Jun 2008. Disponível em: < http://www.fsma. edu.br/visoes/ed04/4ed O Desafio Do Desenvolvimento Sustentavel Gisele. pdf>. Acesso em: 3 maio 2018.

BRASIL. Constituição da República Federativa do Brasil. Brasília, DF: Senado Federal: Centro Gráfico, 1988.

BRASIL. Secretaria de Educação Fundamental. Parâmetros Curriculares Nacionais: Meio ambiente, Saúde/Secretaria de Educação Fundamental. Brasília, 1997. p. 188.

KIST, A.C.F. Concepções e práticas de educação ambiental: uma análise a partir das matrizes teóricas e epistemológicas presentes em escolas estaduais de ensino fundamental de Santa Maria - RS. Dissertação de mestrado, Programa de Pós-Graduação em Geografia e Geociências, da Universidade Federal de Santa Maria (UFSM, RS), 2010. Disponível em: http://w3.ufsm.br/ 
ppggeo/files/dissertacoes 06-11/Anna\%20Cristine.pdf. Acesso em: 3 maio 2018.

LEFF, E. Saber ambiental: sustentabilidade, racionalidade, complexidade, poder. 2 ed. Petrópolis: Rio de Janeiro: Vozes, 2001.

LEITE, A.L.T.A.; MININNI-MEDINA, N. Educação Ambiental: curso básico a distância: educação e Educação Ambiental II. Coordenação-Geral:. Brasília: MMA, 2000,4v.

ROOS, A.; BECKER, E.L.S., Educação Ambiental e Sustentabilidade. Revista Eletrônica em Gestão, Educação e Tecnologia Ambiental - REGET/UFSM (e-ISSN: 2236-1170), v.5, n`5, p. 857 - 866, 2012. Disponível em: $<$ http://periodicos.ufsm.br/reget/article/viewfile/4259/3035>. Acesso em: 3 maio 2018.

SILVA, D.G. A importância da educação ambiental para a sustentabilidade. Trabalho de Conclusão de Curso, Curso de Ciências Biológicas com ênfase em Gestão Ambiental da Faculdade Estadual de Educação, Ciências e Letras de Paranavaí - FAFIPA, 2012. Disponível em: $<$ http://www.uniedu.sed.sc.gov.br/wp-content/uploads/2014/04/DANISE-GUIMA RAES-DA-SILVA.pdf> Acesso em: 3 maio 2018.

em: 3 maio 2018. 